\title{
Research Paper: Relationships Between Functional Movement Screen and Pain, Dynamic Balance, and Trunk Muscle Endurance in Military Personnel With Non-specific Chronic Low Back Pain
}

Seyyed Mojtaba Soltandoost Nari ${ }^{1}$ (D, Alireza Shamsoddini ${ }^{2}$ (D)

1. Department of Sports Injuries and Corrective Exercises, School of Sports Sciences, Ferdowsi University of Mashhad, Mashhad, Iran.

2. Department of Rehabilitation, Exercise Physiology Research Center, Life Style Institute, Baqiyatallah University of Medical Sciences, Tehran, Iran.

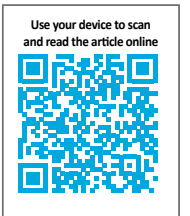

Citation Soltandoost Nari SM, Shamsoddini A. Relationships Between Functional Movement Screen and Pain, Dynamic Balance, and Trunk Muscle Endurance in Military Personnel With Non-specific Chronic Low Back Pain. Physical Treatments. 2020; 10(4):221-230. http://dx.doi.org/10.32598/ptj.10.4.457.1

\section{(c) (1) (8)}

Article info:

Received: 04 May 2020

Accepted: 14 Sep 2020

Available Online: 01 Oct 2020

Keywords:

Functional movement screen, Non-specific chronic low back pain, Dynamic balance, Trunk muscle endurance

\begin{abstract}
A B S T RA C T
Purpose: Functional disability, impaired balance, and trunk muscle endurance are among the major changes in patients with Non-specific Chronic Low Back Pain (NCLBP). Investigating the relationship between these factors and Functional Movement Screen (FMS) can facilitate effective pain management and functional problems in these patients. This study aimed to assess the relationships between FMS and pain, dynamic balance, and trunk muscle endurance in military personnel with NCLBP.
\end{abstract}

Methods: The present study was of a correlational research design. The study subjects were 50 male military personnel with NCLBP (Mean \pm SD age $=33.30 \pm 3.94 \mathrm{y}$, height $=175.32 \pm 5.50 \mathrm{~cm}$, $\&$ weight $=74.05 \pm 3.64 \mathrm{~kg}$ ). FMS was evaluated by FMS tests and pain severity was assessed through Quebec Back Pain Disability Scale; the dynamic balance was evaluated by Y-Balance Test (YBT), and the trunk muscle endurance was measured by the ITO test. Statistical analysis was performed by SPSS. Pearson correlation coefficient at a significance level of $\mathrm{P}<0.05$ was used to examine the association between the research variables.

Results: Pain $(\mathrm{P}=0.04, \mathrm{r}=-0.285)$ was negatively correlated with the FMS. The FMS was positively associated with the dynamic balance $(\mathrm{P}=0.014, \mathrm{r}=0.346)$ and trunk muscle endurance $(\mathrm{P}=0.02, \mathrm{r}=0.381)$.

Conclusion: The FMS can be recommended as a functional assessment tools to identify functional deficits in military personnel with NCLBP. The data suggested that the researchers could employ the FMS as a useful tool in designing more effective treatment plans and improving the functional capacity of individuals with CLBP.

\footnotetext{
* Corresponding Author:

Alireza Shamsoddini, PhD

Address: Department of Rehabilitation, Exercise Physiology Research Center, Life Style Institute, Baqiyatallah University of Medical Sciences, Tehran, Iran. Phone: +98 (21) 87554402

E-mail: alirezaot@bmsu.ac.ir
} 


\section{Highlights}

- The study revealed how the related factors in patients with NCLBP are correlated with FMS.

- The results presented a negative correlation between pain and FMS in military personnel with NCLBP.

- The study results indicated a positive correlation between trunk muscle endurance and dynamic balance, and FMS in military personnel with NCLBP.

\section{Plain Language Summary}

Low back pain affects core stability and balance and leads to functional disability. Patients with Chronic Low Back Pain (CLBP) can be evaluated by several assessment tools. However, there is no comprehensive functional assessment tool for evaluating the complex and variable elements of functional movement in patients with CLBP. Recently, FMS has been increasingly used to evaluate fundamental movement patterns and practically identify individuals at risk of injury. The FMS challenge factors include coordination, limb mobility, postural control, balance, as well as core and pelvic stability. Therefore, the FMS may be a useful tool for identifying sensorimotor dysfunctions in patients with CLBP who tend to reduce mobility, balance, core stability, and coordination. This study aimed to assess the relationships between functional movement screen and pain, dynamic balance, and trunk muscle endurance in military personnel with non-specific CLBP.

\section{Introduction}

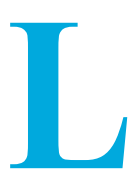

ow Back Pain (LBP) is a prevalent health problem around the world, especially in industrialized countries. According to statistics, about $80 \%$ of individuals in these countries have encountered LBP at least once in their life-

time $[1,2]$. LBP is generally divided into mechanical, rheumatic, infectious, tumoral, and mental categories; among which, mechanical LBP is the most frequent type and accounts for approximately $90 \%$ of total LBP cases [3]. Although it is difficult to define chronic pain, most clinicians agree that LBP will become chronic if not relieved after 6 to 12 weeks with subsequent recurrent pain $[1,2]$. The causes of LBP are different; age, smoking, chronic stress, acute injuries, nutritional disorders, genetics, weight gain, improper weight lifting, decreased flexibility, reduced disc fluid, and poor physical conditions $[4,5]$. Most contemporary views hold the opinion that repeated minor injuries to spinal structures and poor control and stability are major causes of LBP $[4,5]$.

LBP influences the mobility of the lumbar spine and contiguous joints and prompts functional weakness [6]. Accordingly, it is clinically essential to understand LBP and design functional assessments for it. Patients with Chronic Low Back Pain (CLBP) can be surveyed by various objective and subjective assessment tools. The Oswestry Disability Index (ODI), the Roland-Morris
Disability Questionnaire (RMDQ), and the Visual Analog Scale (VAS) are the principal mental devices used to assess the grade of disability. [7, 8]. Some researchers investigated the functional status or functional outcomes acquired after therapeutic intermediation for this condition. The back-endurance test is ordinarily applied to quantify the valence of the back muscles and trunk extensor fatigue $[9,10]$. Individuals with CLBP appear to have decreased trunk muscle strength and a low weariness limit [11].

Measuring spine mobility, aerobic capacity, and trunk strength based on the rating scale are the most common objective tools to evaluate patients with CLBP $[12,13]$. However, there is no comprehensive functional assessment tool for evaluating the complex and variable elements of functional movement in patients with CLBP. Movement assessment allows health and fitness professionals to identify muscle imbalance and strategies for different use of muscles by observing the movement deficits [14]. Functional Movement Screen (FMS) is a method that can detect dysfunctions using translational motion. It can also identify high-risk individuals and evaluate the quality of implementation of functional movement patterns [15].

FMS tests have been widely used in extensive studies; they include 7 scales that identify the limitations and modifications of healthy movement patterns. A maximum score of 21 can be obtained in this test. Previous studies indicated that individuals who obtain scores of 
$\leq 14$ in this test are exposed to damage, especially lower limb organ damage $[15,16]$. For example, O'Connor et al. demonstrated that scores under 14 were related to an improved probability of damage in military personnel [17]. The FMS tests, e.g., deep squat, hurdle step, and lurch tests challenge factors, including coordination, limb mobility, postural control, balance, as well as core and pelvic stability [15]. These tests are intended to cooperate between motor chain mobility and the stability required to perform functional movement patterns. Besides, they essentially measure neuromuscular coordination status, especially core stability and balance. Bringing down the stability and mobility diminishes the individuals' FMS test scores and puts them at further serious risks of injury $[17,18]$.

Numerous studies have evaluated the individual function and predicted the odds of damage through FMS as well as its relationship with the risk factors of damage [19-22]. Kiesel et al. [19] investigated the FMS scores and their association with pre-season injury rates in American football players. They reported that players, who were scored $\leq 14$ were twice as likely to experience skeletal muscle injuries, compared to the players with scores $>14$ [19]. Mitchell et al. [20] documented a positive correlation between core stability and FMS in students $(n=77$, age $=8-11$ years). Teyhen et al. [21] also found a positive relationship between FMS and back muscle endurance, YBT scores, and the flexibility of healthy soldiers. Contrarily, Parchmann et al. [22] observed no association between FMS and sport function. They intended to characterize whether FMS scores or 1RM is associated with athletic performance, explicitly in the division, I golf players regarding sprint times, Vertical Jump (VJ) height, agility t-test times, and clubhead speed (15 men, 10 women, age $=20$ years). They stated that such absence of correlation reflects that FMS is not a proportionate field test and fails to associate with any part of athletic performance. Accordingly, the 1RM squat strength test could be a reliable index of athletic performance.

Despite the widespread use of FMS in studies, scholars overlooked exploring the relationship between FMS and other assessment tools in patients with LBP. Evidence suggests that individuals with LBP have less muscle endurance, balance, and core stability, compared to the healthy population [23, 24]. These patients face deficiencies in the physiological components of afferents and efferents that control balance and decrease stiffness, muscle strength, and endurance. Balance disorder has been frequently reported in patients with LBP [25, 26]. Therefore, FMS may be a useful tool for identifying sensorimotor dysfunctions in patients with CLBP who tend to reduce mo- bility, balance, core stability, and coordination. Therefore, the present study aimed to evaluate the movement function of military personnel with Non-specific Chronic Low Back Pain (NCLBP) through FMS. We also investigated the relationship between the scores of this test and pain, dynamic balance, and trunk muscle endurance.

\section{Materials and Methods}

The present study was of a correlational research design. The statistical population consisted of male military personnel with NCLBP with an age range of 30-40 years. The study inclusion criteria were having pain between the $12^{\text {th }}$ rib and back gluteal fold for more than three months without any pathological evidence. The exclusion criteria of the study were having no known disease affecting research variables, such as osteoporosis, spinal disorders (spondylus, fracture, etc.), spine infection, intervertebral disc spondylolisthesis, sciatica, surgery history, abnormalities in the upper and lower extremities, and too much muscle hypermobility. The statistical samples of the study consisted of 50 men selected by a convenience and purposive sampling method. The required sample size was calculated using data from previous research and $\mathrm{G}$ power software ( $\alpha$ level of 0.05 , a power of $80 \%, \&$ an effect size of 0.5 ) [26].

The subject selection was conducted through interviews and examination by a specialist based on the inclusion and exclusion criteria of the research. Before performing the measurements, the researcher provided sufficient information about the research purpose and the measurement method to the study participants to participate in the study with complete knowledge and consent. However, no explanation was provided on the scoring and its correct method to gain the highest possible scores. The written informed consent forms were obtained from the study individuals. Pain, dynamic balance and trunk muscle endurance were measured by the Quebec Back Pain Disability Scale (QBPDS), Y-balance Test (YBT), and Ito test; the FMS was also performed by FMS tests.

LBP was measured using the QBPDS. The questionnaire contained 25 five-option questions in which pain was scored from zero to 100 . Score zero represents perfect health without pain, $25=$ medium pain, $50=$ severe pain, $75=$ very severe pain, and $100=$ acute pain. In the previous studies, the validity of QBPDS was verified in assessing LBP and reported by $84 \%$. The reliability of the test was also reported to be 0.92 [27].

The YBT was used to measure dynamic balance in the study subjects. It is a reliable and valid assessment tool 
for dynamic balance $(\alpha=0.86-0.95)$ [28]. The test was performed with the subject standing at the center of the platform with 3 cloth tape measures attached to the floor; one in the anterior direction and others positioned $135^{\circ}$ from the anterior tape. The study subjects performed the single-leg stance test while extending the other leg as far as possible along with the reach directions (anterior, posteromedial, \& posterolateral) (Figure 1).

When the reaching foot touched the furthest point possible, the subject returned to the bilateral stance position while maintaining balance. The examiner measured the distance from the center of the grid to the touchpoint. Reach distance was then normalized by dividing it by the research subject's limb length and subsequently multiplying it by 100 [29]. The study subject's limb length was measured using a cloth tape measure from the anterior superior iliac spine to the medial malleolus tip in lie-down position. Before conducting the tests, each research subject performed 6 practice trials to minimize the learning effect [30], followed by a rest period. Next, they performed 3 trials per direction on the stance foot. The mean normalized score of 3 trials was recorded as the study subject's YBT score.

To prevent the effect of testing order on the data, the starting direction was randomly selected via the specified cards. The trials were repeated if the study subject failed to keep hands on the hips, used the reaching foot for stance support, or failed to maintain unilateral stance on the platform. Each subject was requested to perform this test at the beginning and end of the study. Composite reach distance was measured as the sum of 3 reach directions (anterior, posteromedial, \& posterolateral), divided by 3 times of limb length, then multiplied by 100 [29, 30].

The Ito test was employed to measure the flexor and extensor muscle endurance. To assess the endurance of trunk flexor muscles, the research participants were put in a supine position on the bed as they held their lower extremities while the objects were vertical, and the legs were fully horizontal. They also bent their hands to the abdomen while bending head and neck forward and upward. The duration of time, when a person can maintain this position, was recorded in seconds using a timer by the examiner; this value was considered as the isometric muscle endurance of trunk flexors. The test would be stopped if the examiner was unable to maintain the position or released the muscle contraction. The reliability of the test was reported to be 0.97 and 0.93 for healthy participants and those with LBP, respectively [31].
The participants lied prone to measure the endurance of back muscles. A small pillow was placed beneath their stomach to reduce the waist bezel. The research participants were then requested to bend heads as far as possible and remove and hold their sternum. The duration of maintaining this position was recorded by the examiner and considered as the endurance of trunk extensor muscles. The test was stopped when the study individuals were unable to maintain the position or released the contraction. The reliability of the test was reported to be 0.97 for healthy participants, and from 0.93 to 0.95 for those with LBP [31].

The FMS tests included 7 inventories; deep squat, hurdle step, inline lunge, shoulder mobility, active straight leg raise, trunk stability pushup, and rotary stability [15] (Figure 2). The method of scoring these tests was conducted per the instructions by Cook and associates. Therefore, score 3 was considered for correct movement without compensatory movements; score 2 for movement with compensatory movements; score 1 for inability to move without compensatory movements, and score 0 was considered for pain during movement or clearing test. Five out of seven tests (hurdle step, inline lunge, shoulder mobility, active straight leg-raise, \& rotary stability) were independently scored on the right and left sides of the body. The FMS scoring system emphasized the asymmetry due to neuromuscular asymmetry between right and left sides. Besides, the lowest score was considered as the overall value for that specific move. To obtain the final score, the total scores of each test were summed [32]. The scores below 14 were considered as a predictor of injury

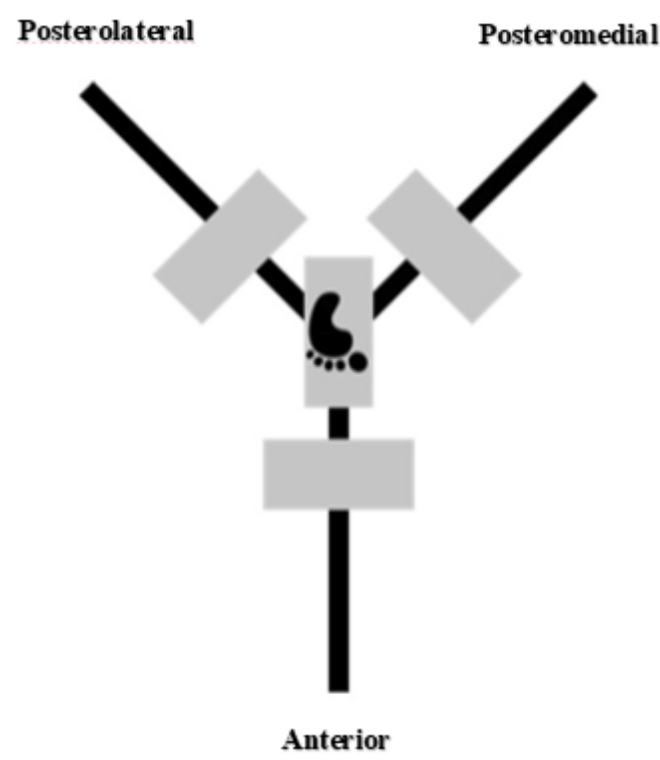

PHYSICAL TREA $\$ MENTS

Figure 1. YBT reach directions for both feet 


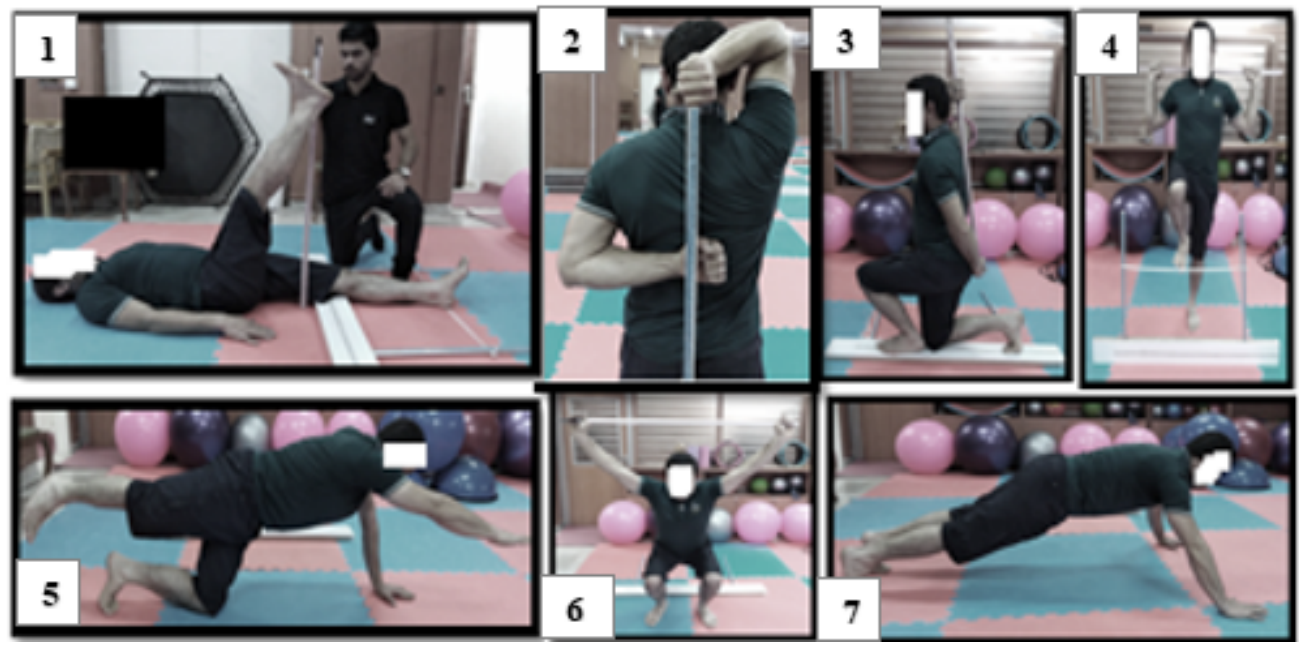

Figure 2. Functional Movement Screening Tests

PHYSICAL TREA TMENTS

1. active straight leg-raise; 2 . shoulder mobility; 3 . inline lunge; 4 . hurdle step; 5 . rotary stability; 6 . deep squat; 7 . trunk stability pushup

risk [15-17]. The moderate to good inter-and intra-rater reliability was reported for this test [33].

Statistical analysis was performed by SPSS using descriptive and inferential statistics. The Shapiro-Wilk test was applied to examine the normality of the data. Pearson correlation coefficient was used to investigate the relationship between the scores of the FMS test and pain severity, dynamic balance, and trunk muscle endurance. $\mathrm{P}<0.05$ was considered as the significance level.

\section{Results}

Table 1 presents the mean and standard deviation values of the demographic characteristics of the study participants, including age, height, and weight. Table 2 lists the mean and standard deviation of FMS scores. The Pearson correlation test results indicated a significant and positive relationship between FMS test and dynamic balance, and trunk muscle endurance; it also suggested a significant and negative relationship between FMS and pain severity. Table 3 and Figure 3 present the related test results.

\section{Discussion}

Table 1. Demographic characteristics of the study participants

\begin{tabular}{cc}
\hline Variables & Mean \pm SD \\
\hline Age $(\mathrm{y})$ & $33.30 \pm 3.94$ \\
Height $(\mathrm{cm})$ & $175.32 \pm 5.50$ \\
Weight $(\mathrm{kg})$ & $74.05 \pm 3.64$ \\
\hline
\end{tabular}

PHYSICAL TREA $\mid$ MENTS
The present study aimed to evaluate the functional movement in military personnel with NCLBP through FMS. Additionally, we assessed the correlation between the scores of the FMS test and pain severity, balance, and trunk muscle endurance. The obtained results indicated a significant positive correlation between FMS and dynamic balance and trunk muscle endurance. Furthermore, there was a significant negative correlation between FMS and pain severity. There exists a few studies on the association of FMS and some factors, including pain, balance, and trunk muscle endurance in individuals with NCLBP.

The study evaluated the functions of military personnel with NCLBP through an FMS test. The scale included 7 tests; deep squat, hurdle step, inline lunge, shoulder mobility, active straight leg raise, trunk stability pushup, and rotary stability. Among the 7 tests of FMS, deep squat, inline lunge, and hurdle step tests examine core stability factors, gluteal strength, proprioception, as well as the balance and stability of hip, knee, and ankle. Active straight leg raising challenged the flexibility of hamstring and cuff muscles, and trunk stability pushup and rotary stability challenged the trunk stability [15]. 
Table 2. Mean \pm SD values of FMS

\begin{tabular}{ccc}
\hline Variables & Mean \pm SD \\
\hline DP & $1.14 \pm 0.60$ \\
\hline HS & $1.32 \pm 0.76$ \\
\hline ILL & $1.48 \pm 0.83$ \\
\hline SM & $2.20 \pm 0.78$ \\
\hline ASLR & $1.60 \pm 0.67$ \\
\hline TSP & $1.80 \pm 0.83$ \\
RS & $1.32 \pm 0.79$ \\
\hline Total FMS & $10.86 \pm 1.27$ \\
\hline
\end{tabular}

DP: deep squat; HS: hurdle step; ILL: inline lunge; SM: shoulder mobility; ASLR: active straight leg-raise; TSP: trunk stability pushup; RS: rotary stability.

In the present study, the mean total FMS score equaled 10.86 out of 21 ; the study participants' scores ranged from 9 to 13 . O'Connor et al. found that scores below
14 were associated with an increased odds of injury in military personnel [17]. Previous studies reported a significant direct relationship between a history of LBP and

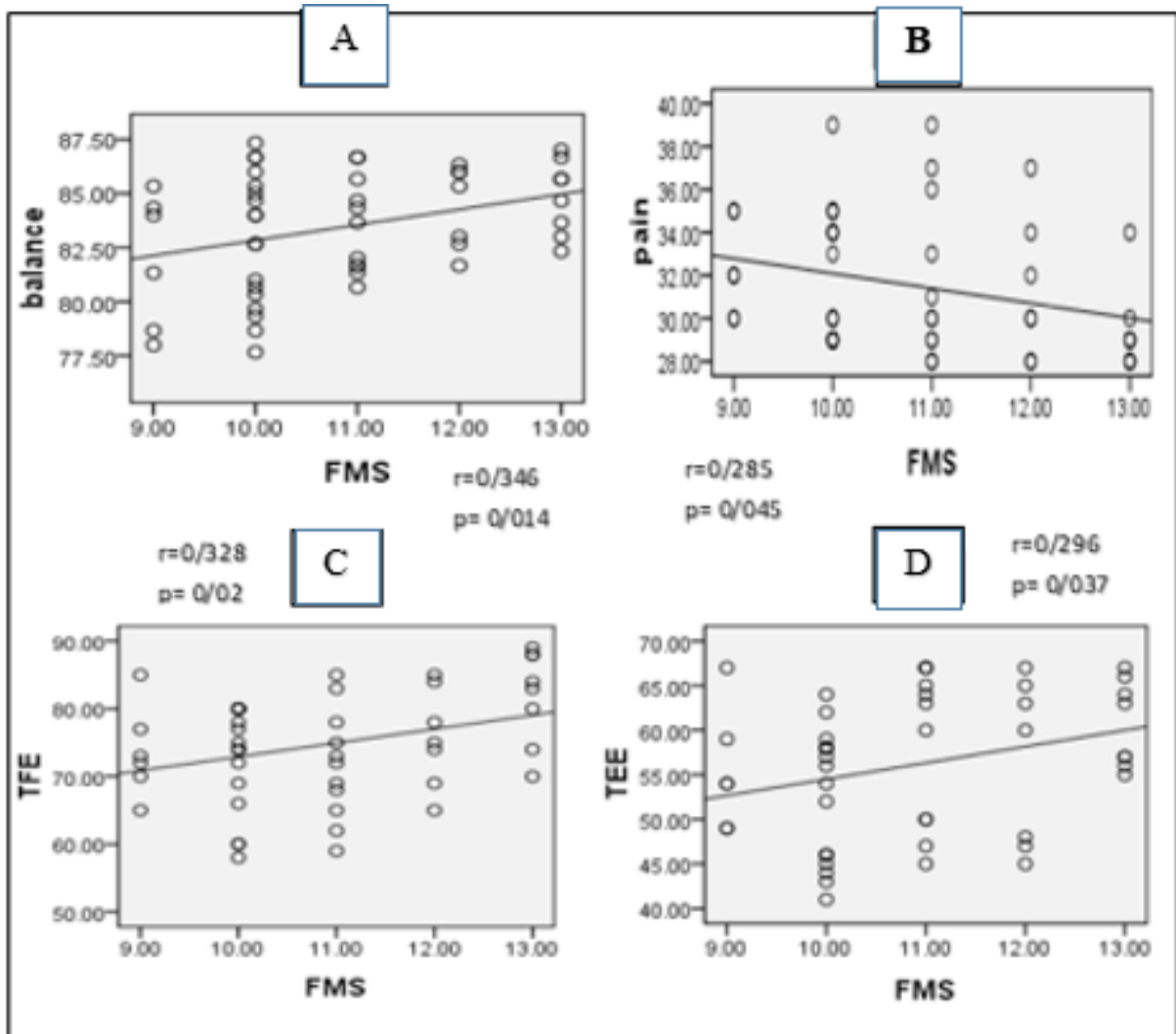

Figure 3. Correlation between FMS and balance, pain severity, and trunk muscle endurance

PHYSICAL TREATMENTS

A. Correlation between FMS and balance

B. Correlation between FMS and pain severity

C. Correlation between FMS and Trunk Flexor Endurance (TFE)

D. Correlation between FMS and Trunk Extensor Endurance (TEE) 
Table 3. Pearson correlation test results

\begin{tabular}{|c|c|c|c|c|c|c|c|c|}
\hline & Variables & Pain & $\begin{array}{l}\text { YBT Posteromedial } \\
\text { Reach }\end{array}$ & $\begin{array}{l}\text { YBT Posterolat- } \\
\text { eral Reach }\end{array}$ & $\begin{array}{l}\text { YBT Ante- } \\
\text { rior Reach }\end{array}$ & $\begin{array}{l}\text { Overall } \\
\text { YBT Score }\end{array}$ & $\begin{array}{c}\text { Endurance } \\
\text { Trunk Flexor } \\
\text { Muscles }\end{array}$ & $\begin{array}{l}\text { Endurance } \\
\text { Trunk Exten- } \\
\text { sor Muscles }\end{array}$ \\
\hline & Mean $\pm S D$ & $31.50 \pm 3.11$ & $84.24 \pm 3.10$ & $83.38 \pm 2.83$ & $82.74 \pm 2.97$ & $83.75 \pm 2.62$ & $56.08 \pm 7.89$ & $74.68 \pm 7.98$ \\
\hline \multirow[t]{2}{*}{ FMS } & $\begin{array}{l}\text { Pearson } \\
\text { correlation } \\
\text { coefficient }\end{array}$ & -0.285 & 0.317 & 0.285 & 0.312 & 0.346 & 0.328 & 0.296 \\
\hline & $P$ & 0.045 & 0.025 & 0.047 & 0.027 & 0.014 & 0.02 & 0.037 \\
\hline
\end{tabular}

lower active straight leg raising [21]. Moreover, Shum et al. [34] reported that individuals with CLBP presented limited movement in sitting to standing movements in the lumbar vertebrae and pelvis, and vice versa. Sung et al. [35] also argued that the kinetic and kinematic stability of individuals with CLBP were decreased during the single-leg stance; their balance functions were impaired, leading to alternations in their proprioception and postural control. Some studies also reported a decrease in spine mobility, endurance, strength, and fitness in individuals with CLBP [36-38].

Furthermore, a low total FMS score was associated with lower movement function, as well as disabilities in the explored military personnel with CLBP. The current study results indicated a significant positive correlation between the trunk muscle endurance and score of FMS $(\mathrm{r}=0.381)$. A proper explanation for this result could be the poor endurance of flexor and extensor trunk muscles, and the defective body coordination and movement. Trunk endurance was measured by calculating the period when a subject could hold the trunk in an unsupported state. The trunk muscles play important roles in supporting and stabilizing the lumbar spine $[39,40]$. Trunk muscle endurance is correlated with low fatigue thresholds and leads to the non-control of trunk movement [39]. Mitchell et al. [20] found a significant correlation between overall FMS scores and core stability and dynamic posture. FMS measures trunk stability through trunk stability pushup, rotary stability, squat, lunge, and hurdle step tests $[15,32]$.

The present study data also indicated a significant correlation between the scores of FMS and YBT $(\mathrm{r}=0.346)$. Given that the correlation was moderate, the results of the two tests were correlated; the better the balance, the greater the FMS score. Lockie et al. [41] compared FMS scores with Star Excursion Balance (SEB) test values. They reported a direct relationship between the rotary stability test scores and the trunk stability pushup in FMS and SEB tests. Another study specified a significant relationship between rotary stability score and trunk stability pushup in FMS, and the anterior reaching in the SEB test [42]. In these studies, the participants performed the SEB test in 8 directions; however, in the present study, we used the YBT in 3 directions.

The previous study suggested that reaching in the SEB test could not be compared with FMS scores [42]; however, we detected a significant negative correlation between FMS scores and pain severity $(\mathrm{r}=-0.285)$. The result was obtained from comparing the study participants' total pain scores in the QBPDS. The scale probed questions about the state of pain and functions of daily living activities in individuals with LBP. The correlation of the FMS and pain severity could help to better evaluate physical function and abilities in individuals with CLBP. Besides, it could be beneficial for designing prevention programs regarding the reduction of their movement functions.

The current research limitations incorporated the absence of controls over the subjects' nourishing status that may influence the research subjects' performance. The lack of assessing muscle length was another constraint of this research. Muscle length can influence individuals' performance in multiple tests. Other limitations contained overlooking the exact control of biopsychological status, e.g., the subjects' attitude, motivation, and nervousness levels during training and examinations.

\section{Conclusion}

Our study identified the relationship between pain, trunk muscle endurance, and dynamic balance, and FMS. The relevant outcomes demonstrated a negative relationship between pain and FMS scores. There was also a positive correlation between trunk muscle endurance and dynamic balance, and FMS. Therefore, FMS can be recommended as a functional assessment tool to identify functional deficits in military personnel with NCLBP. The data suggested that the researchers could employ FMS as a useful tool for designing more effective treatment plans and improving the functional capacity of subjects with CLBP. 


\section{Ethical Considerations}

\section{Compliance with ethical guidelines}

The study was approved by the Ethics Committee of Exercise Physiology Research Center of Baqiyatallah University of Medical Sciences (Code: IR.BMSU. REC.1396.525).

\section{Funding}

This research did not receive any grant from funding agencies in the public, commercial, or non-profit sectors.

\section{Authors' contributions}

All authors equally contributed to preparing this article.

\section{Conflict of interest}

The authors declared no conflicts of interest.

\section{References}

[1] Damasceno LHF, Catarin SRG, Campos AD, Defino HLA. Lumbar lordosis: A study of angle values and of vertebral bodies and intervertebral discs role. Acta Ortopedica Brasileira. 2006; 14(4):193-8. [DOI:10.1590/S1413 78522006000400003]

[2] Reid M. An assessment of health needs of chronic low back pain patients from general practice. Journal of Health Psychology. 2004; 9(3):451-62. [DOI:10.1177/1359105304042353] [PMID]

[3] Kiani Dehkordi K, Ebrahim K, Frastic S. [Effective treatment of stretch step to keep changes in the face of resistance and liberation of the hip joint in patients with chronic low back pain (Persian)]. Journal of Movement Science and Sport 2008; 2(12):11-22. http://ensani.ir/file/download/article/20120326111157-1128-38.pdf

[4] Lee GK, Chronister J, Bishop M. The effects of psychosocial factors on quality of life among individuals with chronic pain. Rehabilitation Counseling Bulletin. 2008; 51(3):177-89. [DOI:10.1177/0034355207311318]

[5] Hodges PW. Core stability exercise in chronic low back pain. The Orthopedic clinics of North America. 2003; 34(2):245-54 [DOI:10.1016/s0030-5898(03)00003-8] [PMID]

[6] Wong TKT, Lee RYW. Effects of low back pain on the relationship between the movements of the lumbar spine and hip. Human Movement Science. 2004; 23(1):21-34. [DOI:10.1016/j.humov.2004.03.004] [PMID]

[7] Roland M, Fairbank J. The Roland-Morris disability questionnaire and the Oswestry disability questionnaire. Spine. 2000; 25(24):3115-24. [DOI:10.1097/00007632-20001215000006] [PMID]
[8] Han G, Cho M, Nam G, Moon T, Kim J, Kim S, et al. The effect on muscle strength and viual analog scale pain of aquatic therapy for individuals with low back pain. Journal of Physical Therapy Science, 2011; 23:57-60. [DOI:10.1589/jpts.23.57]

[9] Coorevits P, Danneels L, Cambier D, Ramon H, Vanderstraeten G. Assessment of the validity of the Biering-Sørensen test for measuring back muscle fatigue based on EMG median frequency characteristics of back and hip muscles. Journal of Electromyography and kinesiology. 2008, 18(6):997-1005. [DOI:10.1016/j.jelekin.2007.10.012] [PMID]

[10] Biering-Sørensen F. Physical measurements as risk indicators for low-back trouble over a one-year period. Spine. 1984; 9(2):106-19. [DOI:10.1097/00007632-198403000-00002] [PMID]

[11] Latimer J, Maher CG, Refshauge K, Colaco I. The reliability and validity of the Biering-Sorenson test in asymptomatic subjects and subjects reporting current or previous nonspecific low back pain. Spine. 1999; 24(20):2085-9. [DOI:10.1097/00007632-199910150-00004] [PMID]

[12] Kishi S, Morikita I. Range of motion of hip joints of male university kendo practitioners with lower back pain. Journal of Physical Therapy Science. 2009; 21(3):253-6. [DOI:10.1589/ jpts.21.253]

[13] McQuade KJ, Turner JA, Buchner DM. Physical fit nes and chronic low back pain: An analysis of the relationships among fitness, functional limit actions, and depression. Clinical Orthopaedics and Related Research. 1988; (233):198-204. [DOI:10.1097/00003086-198808000-00023]

[14] Bagherian S, Ghasempoor K, Rahnama N, Wikstrom EA The effect of core stability training on functional movement patterns in college athletes. Journal of Sport Rehabilitation. 2019; 28(5):444-9. [DOI:10.1123/jsr.2017-0107] [PMID]

[15] Cook G. Movement: Functional movement systems: Screening, assessment, corrective strategies, 1st edition. Delhi: Lotus Publication; 2010. https://www.amazon.com/MovementFunctional-Assessment-Corrective-Strategies/dp/1905367333

[16] Chorba RS, Chorba DI, Bouillon LE, Overmyer CA, Landis JA. Use of a functional movement screening tool to determine injury risk in female collegiate athletes. North American Journal of Sports Physical Therapy. 2010; 5(2):47-54. [PMID]

[17] O'connor FG, Deuster PA, Davis J, Pappas CG, Knapik JJ. Functional movement screening: Predicting injuries in officer candidates. Medicine \& Science in Sports \& Exercise. 2011 43(12):2224-30. [DOI:10.1249/MSS.0b013e318223522d] [PMID]

[18] Sorenson EA. Functional movement screen as a predictor of injury in high school basketball athletes [PhD. dissertation] Eugene (OR): University of Oregon; 2009. https:/ /scholarsbank.uoregon.edu/xmlui/handle/1794/10594

[19] Kiesel KB, Butler RJ, Plisky PJ. Prediction of injury by limited and asymmetrical fundamental movement patterns in American football players. Journal of Sport Rehabilitation. 2014; 23(2):88-94. [DOI:10.1123/JSR.2012-0130] [PMID]

[20] Mitchell UH, Johnson AW, Adamson B. Relationship between functional movement screen scores, core strength posture, and BMI in school children in Moldova. The Journal of Strength \& Conditioning Research. 2015; 29(5):1172-9. [DOI:10.1519/JSC.0000000000000722] [PMID]

[21] Teyhen DS, Shaffer SW, Lorenson CL, Greenberg MD, Rogers SM, Koreerat CM, et al. Clinical measures associated 
with dynamic balance and functional movement. The Journal of Strength \& Conditioning Research. 2014; 28(5):127283. [DOI:10.1519/JSC.0000000000000272] [PMID]

[22] Parchmann CJ, McBride JM. Relationship between functional movement screen and athletic performance. The Journal of Strength \& Conditioning Research. 2011; 25(12):337884. [DOI:10.1519/JSC.0b013e318238e916] [PMID]

[23] Kofotolis N, Kellis E. Effects of two 4-week proprioceptive neuromuscular facilitation programs on muscle endurance, flexibility, and functional performance in women with chronic low back pain. Physical Therapy. 2006; 86(7):100112. [DOI:10.1093/ptj/86.7.1001] [PMID]

[24] Shakeri A, Sokhangoei Y, Shojaedin S, Hoseini Y. [Comparison between the effect of three methods of massage therapy stability exercise and combination exercise on dynamic stability in patients, with chronic non-specific low back pain during sitting standing tasks (Persian)]. Journal Anesthesiology and Pain. 2015; 6(1):42-53. http://jap.iums.ac.ir/article-1-5217-en.pdf

[25] Ebenbichler GR, Oddsson LI, Kolmttzer J, Erim Z. Sensorymotor control of the lower back: Implications for rehabilitation. Medicine and Science in Sports and Exercise. 2001; 33(11):188998. [DOI:10.1097/00005768-200111000-00014] [PMID]

[26] Safarzadeh M, Daneshjoo AH, Hosseinpour A, Bamorovat F. [Relationship between functional movement screen whit risk factors and its ability to predict sport injuries (Persian)]. Journal of Paramedical Sciences and Rehabilitation. 2018; 8(1):83-92. [DOI:10.22038/JPSR.2019.27275.1713]

[27] Kopec JA, Esdaile JM, Abrahamowicz M, Abenhaim L, WoodDauphinee S, Lamping DL, et al. The Quebec Back Pain Disability Scale: Measurement Properties. Spine. 1995; 20(3):34152. [DOI:10.1097/00007632-199502000-00016] [PMID]

[28] Olmsted LC, Carcia CR, Hertel J, Shultz SJ. Efficacy of the star excursion balance tests in detecting reach deficits in subjects with chronic ankle instability. Journal of Athletic Training. 2002; 37(4):501-6. [PMCID]

[29] Hertel J, Braham RA, Hale SA, Olmsted-Kramer LC. Simplifying the star excursion balance test: Analyses of subjects with and without chronic ankle instability. The Journal of Orthopedic and Sports Physical Therapy. 2006; 36(3):131-7. [DOI:10.2519/jospt.2006.36.3.131] [PMID]

[30] Plisky PJ, Rauh MJ, Kaminski TW, Underwood FB. Star excursion balance test as a predictor of lower extremity injury in high school basketball players. Journal of Orthopaedic \& Sports Physical Therapy. 2006; 36(12):911-9. [DOI:10.2519/ jospt.2006.2244] [PMID]

[31] Ito T, Shirado O, Suzuki H, Takahashi M, Kaneda K, Strax TE. Lumbar trunk muscle endurance testing: An inexpensive alternative to a machine for evaluation. Archives of Physical Medicine and Rehabilitation. 1996; 77(1):75-9. [DOI:10.1016/ S0003-9993(96)90224-5]

[32] Cook G, Burton L, Hoogenboom B. Pre-participation screening: The use of fundamental movements as an assessment of function -- part 1. North American Journal of Sports Physical Therapy. 2006; 1(2):62-72. [PMCID]

[33] Teyhen DS, Shaffer SW, Lorenson CL, Halfpap JP, Donofry DF, Walker MJ, et al. The functional movement screen: A reliability study. Journal of Orthopaedic \& Sports Physical Therapy. 2012; 42(6):530-40. [DOI:10.2519/jospt.2012.3838] [PMID]
[34] Shum GLK, Crosbie J, Lee RYW. Effect of low back pain on the kinematics and joint coordination of the lumbar spine and hip during sit-to-stand and stand-to-sit. Spine. 2005; 30(17):19982004. [DOI:10.1097/01.brs.0000176195.16128.27] [PMID]

[35] Sung PS, Yoon B, Lee DC. Lumbar spine stability for subjects with and without low back pain during one-leg standing test. Spine. 2010; 35(16):E753-60. [DOI:10.1097/ BRS.0b013e3181d53b9c] [PMID]

[36] Cleland J, Gillani R, Bienen EJ, Sadosky A. Assessing dimensionality and responsiveness of outcomes measures for subjects with low back pain. Pain Practice. 2011; 11(1):57-69. [DOI:10.1111/j.1533-2500.2010.00390.x] [PMID]

[37] Parks KA, Crichton KS, Goldford RJ, McGill SM. A comparison of lumbar range of motion and functional ability scores in subjects with low back pain: Assessment for range of motion validity. Spine. 2003; 28(4):380-4. [DOI:10.1097/00007632-200302150-00014] [PMID]

[38] Wittink H. Functional capacity testing in subjects with chronic pain. The Clinical Journal of Pain. 2005; 21(3):197-9. [DOI:10.1097/00002508-200505000-00001] [PMID]

[39] Parianpour M, Nordin M, Kahanovitz N, Frankel V. 1988 volvo award in biomechanics: The triaxial coupling of torque generation of trunk muscles during isometric exertions and the effect of fatiguing isoinertial movements on the motor output and movements patterns. Spine. 1988; 13(9):982-92. [DOI:10.1097/00007632-198809000-00004] [PMID]

[40] Takemasa R, Yamamoto H, Tani T. Trunk muscle strength in and effect of trunk muscle exercises for subjects with chronic low back pain. Spine. 1995; 20(23):2522-30. [DOI:10.1097/00007632-199512000-00012] [PMID]

[41] Lockie RG, Callaghan SJ, Moreno MR, Risso FG, Liu TM, Stage AA, et al. Certain actions from the Functional Movement Screen do not provide an indication of dynamic stability. Journal of Human Kinetics. 2017; 60:19-28. [DOI:10.1515/ hukin-2017-0109] [PMID] [PMCID]

[42] Lockie RG, Schultz AB, Callaghan SJ, Jordan CA, Luczo TM, Jeffriess MD. A preliminary investigation into the relationship between functional movement screen scores and athletic physical performance in female team sport athletes. Biology of Sport. 2015; 32(1):41-51. [DOI:10.5604/20831862.1127281] [PMID] [PMCID] 
This Page Intentionally Left Blank 